\title{
Task Allocation Model for Rescue Disabled Persons in Disaster Area with Help of Volunteers
}

\author{
Kohei Arai \\ Graduate School of Science and \\ Engineering \\ Saga University \\ Saga City, Japan
}

\author{
Tran Xuan Sang \\ Faculty of Information Technology \\ Vinh University \\ Vinh City, Vietnam
}

\author{
Nguyen Thi Uyen \\ Faculty of Information Technology \\ Vinh University \\ Vinh City, Vietnam
}

\begin{abstract}
In this paper, we present a task allocation model for search and rescue persons with disabilities in case of disaster. The multi agent-based simulation model is used to simulate the rescue process. Volunteers and disabled persons are modeled as agents, which each have their own attributes and behaviors. The task of volunteers is to help disabled persons in emergency situations. This task allocation problem is solved by using combinatorial auction mechanism to decide which volunteers should help which disabled persons. The disaster space, road network, and rescue process are also described in detail. The RoboCup Rescue simulation platform is used to present proposed model with different scenarios.
\end{abstract}

Keywords- Task Allocation Model; Multi Agent-based Rescue Simulation; Auction based Decision Making.

\section{INTRODUCTION}

Persons with disabilities suffer a much higher risk in the case of disasters than persons without disabilities. The data of recent disasters i.e. Tsunami, Katrina and earthquake shows that the mortality of disabled people during the disaster were very high (Ashok Hans, 2009). The reason for this is because many handicapped people may face physical barriers or difficulties of communication that they are not able to respond effectively to crisis situations. They were not able to evacuate by themselves. Obviously, disabled people need assistances to evacuate.

While in the past, persons with disabilities were not taken in consideration during the planning and mitigation of disaster management, in more recent years, this group of population has been realized as a prior target to help in emergency situations. It is important to learn the needs of persons with disabilities and the various forms of disabilities in order to help them effectively and minimize the mortality. The rescue process for persons with disabilities is a dynamic process under uncertainty and emergency, therefore it is not easy to predict what will happen in the rescue process. In that case, the computer simulation can be used to simulate the rescue process with various scenarios in the disaster area.

Most computer based simulation evacuation models are based on flow model, cellular automata model, and multiagent-based model. Flow based model lacks interaction between evacuees and human behavior in crisis. Cellular automata model is arranged on a rigid grid, and interact with one another by certain rules [1]. A multi agent-based model is composed of individual units, situated in an explicit space, and provided with their own attributes and rules [2]. This model is particularly suitable for modeling human behaviors, as human characteristics can be presented as agent behaviors. Therefore, the multi agent-based model is widely used for evacuation simulation [1-4].

Recently, Geographic Information Systems (GIS) is also integrated with multi-agent-based model for emergency simulation. GIS can be used to solve complex planning and decision making problems [5-7]. In this study, GIS is used to present road network with attributes to indicate the road conditions.

We develop a task allocation model for search and rescue persons with disabilities and simulate the rescue process to capture the phenomena and complexities during evacuations. The task allocation problem is presented by decision of volunteers to choose which victims should be helped in order to give first-aid and transportation with the least delay to the shelter. The decision making is based on several criteria such as health condition of the victims, location of the victims and location of volunteers.

The rest of the paper is organized as follows. Section 2 reviews related works. Section 3 describes the proposed rescue model and the task allocation model. Section 4 provides the experimental results of different evacuation scenarios. Finally, section 5 summarizes the work of this paper.

\section{RELATED WORKS}

There is considerable research in emergency simulation by using GIS multi-agent-based models. Ren et al. (2009) presents an agent-based modeling and simulation using Repast software to construct crowd evacuation for emergency response for an area under a fire. Characteristics of the people are modeled and tested by iterative simulation. The simulation results demonstrate the effect of various parameters of agents. Zaharia et al. (2011) proposes agent-based model for the emergency route simulation by taking into account the problem of uncharacteristic action of people under panic condition given by disaster. Drogoul and Quang (2008) discuss the intersection between two research fields: multi-agent system and computer simulation. This paper also presents some of the current agentbased platforms such as NetLogo, Mason, Repast, and Gama. Bo and Satish (2009) presents an agent-based model for 
hurricane evacuation by taking into account the interaction among evacuees. For the path finding, the agents can choose the shortest path and the least congested route respectively. Cole (2005) studied on GIS agent-based technology for emergency simulation. This research discusses about the simulation of crowding, panic and disaster management. Quang et al. (2009) proposes the approach of multi-agent-based simulation based on participatory design and interactive learning with experts' preferences for rescue simulation. Silvia et al. (2005), Ranjit et al. (2001) and Santos et al. (2010) apply the auction mechanism to solve the task allocation problem in rescue decision making.

Through the view of this background, this study will focus mainly on task allocation for volunteers to help disabled persons. With effective task allocation method, it can improve the rescue process. By considering the number of volunteers, number of disabled persons and traffic condition as changing parameters, we also draw the correlations between these parameters and rescue time.

\section{Rescue AND TASK Allocation Model}

\section{A. Rescue Simulation Model}

The ability to receive critical information about an emergency, how to respond to an emergency, and where to go to receive assistance are crucial components of an evacuation plan. In practical evacuation process, we assume that after the warning is issued; all disabled persons send information to the emergency center via a special device. This device measures the condition of the disabled persons such as heart rate and body temperature; the device can also be used to trace the location of the disabled persons by GPS. Emergency center will collect that information and then broadcast to volunteers' smart-phones through the internet. After checking the condition of victims, volunteers make their own decision to help victims and inform the emergency center.

The centralized rescue model is presented which has three types of agent: volunteers, disabled people and route network. The route network is also considered as an agent because the condition of traffic in certain route can be changed when disaster occurs. The general rescue model is shown in Figure 1.

II.

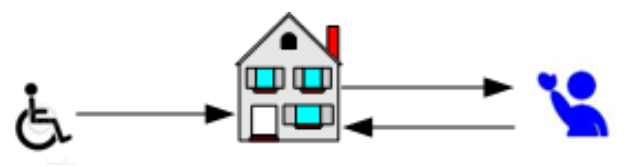

Figure 1. Centralized Rescue Model

In simulation environment, we try to set up as close as possible to these above assumptions. Before starting simulation, every agent has to be connected to the emergency center in order to send and receive information. The types of data exchanged between agents and emergency center are listed as below.

Message from agent

A1: To request for connection to the emergency center

A2: To acknowledge the connection

A3: Inform the movement to another position

A4: Inform the rescue action for victim

\section{A5: Inform the load action for victim}

A6: Inform the unload action for victim

A7: Inform the inactive status

Message from emergency center

K1: To confirm the success of the connection

$\mathrm{K} 2$ : To confirm the failure of the connection

$\mathrm{K} 3$ : To send decisive information

Before starting simulation, every agent will send the command A1 to request for connection to the emergency center. The emergency center will return the response with command $\mathrm{K} 1$ or $\mathrm{K} 2$ corresponding to the success or failure of connection respectively. If the connection is established, the agent will send the command A2 to acknowledge the connection. The initial process of simulation is shown in Figure 2.

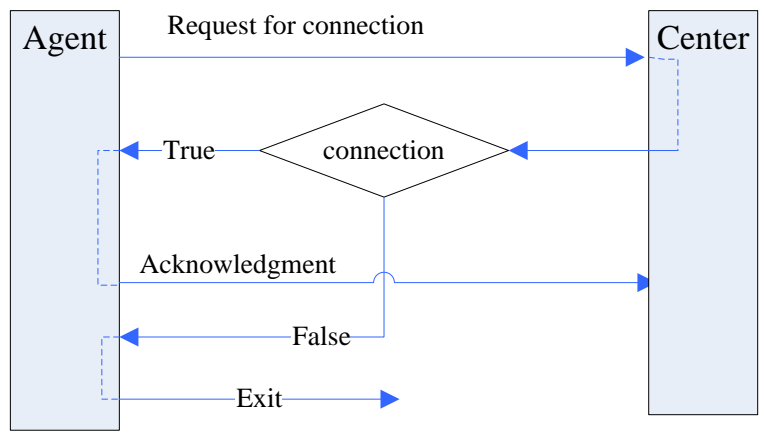

Figure 2. Initial Process

After the initial process, all the connected agents will receive the decisive information such as location of agents and health level via command $\mathrm{K} 3$; after that the rescue agents will make a decision of action and submit to the center using one of the commands from A3 to A7. At every cycle in the simulation, each rescue agent receives a command $\mathrm{K} 3$ as its own decisive information from the center, and then submits back an action command. The status of disaster space is sent to the viewer for visualization of simulation. The repeated steps of simulation are shown in Figure 3.

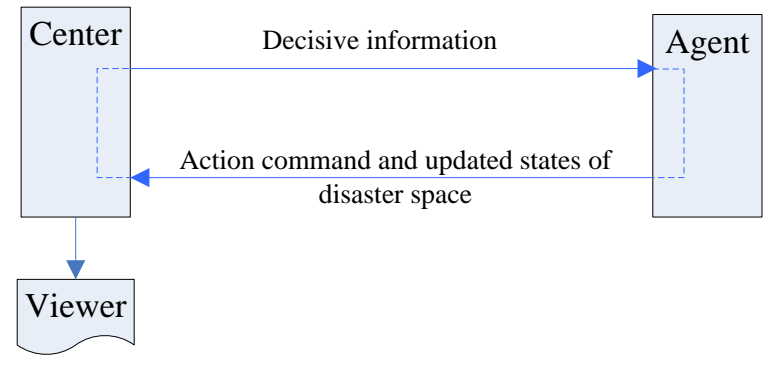

Figure 3. Simulation Cycle

\section{A. Disaster Area Model}

The disaster area is modeled as a collection of objects of Nodes, Buildings, Roads, and Humans. Each object has properties such as its positions, shape and is identified by a unique ID. From table1 to table 4 present the properties of Nodes, Buildings, Roads and Humans object respectively. 
These properties are derived from RoboCup rescue platform with some modifications.

I. PROPERTIES OF NODE OBJECT

\begin{tabular}{|l|l|l|}
\hline Property & Unit & \multicolumn{1}{c|}{ Description } \\
\hline $\mathrm{x}, \mathrm{y}$ & & The $\mathrm{x}$-y coordinate \\
\hline Edges & ID & The connected roads and buildings \\
\hline
\end{tabular}

II. PROPERTIES OF BUILDING OBJECT

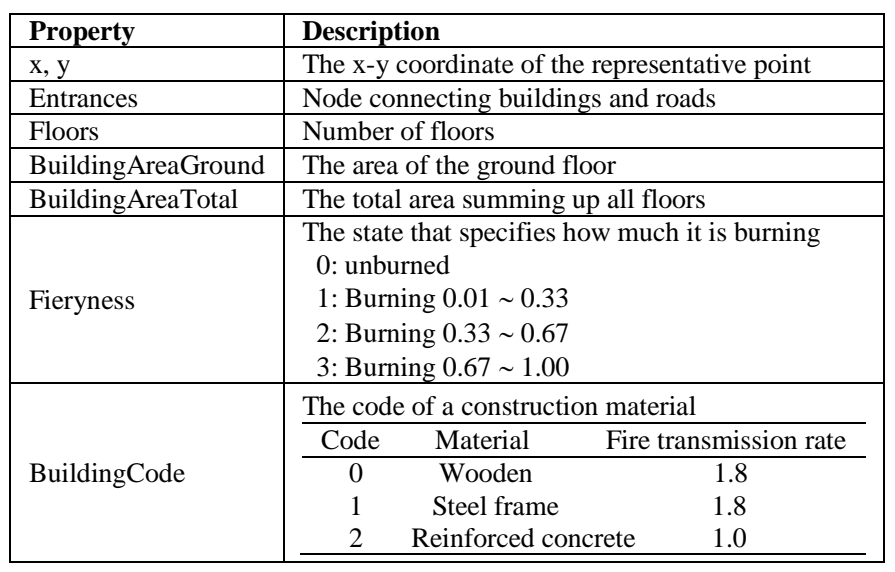

III. PROPERTIES OF ROAD OBJECT

\begin{tabular}{|l|l|l|}
\hline \multicolumn{1}{|c|}{ Property } & \multicolumn{1}{c|}{ Unit } & \multicolumn{1}{c|}{ Description } \\
\hline $\begin{array}{l}\text { StartPoint and } \\
\text { EndPoint }\end{array}$ & ID & $\begin{array}{l}\text { Point to enter the road. It must be the node } \\
\text { or a building }\end{array}$ \\
\hline Length and Width & {$[\mathrm{mm}]$} & Length and width of the road \\
\hline Lane & {$[$ Line $]$} & Number of traffic lanes \\
\hline BlockedLane & {$[$ Line $]$} & Number of blocked traffic lanes \\
\hline ClearCost & {$[$ Cycle $]$} & The cost required for clearing the block \\
\hline
\end{tabular}

IV. TABle 4. PROPERTIES OF HUMANOID OBJECT

\begin{tabular}{|l|l|l|}
\hline Property & Unit & Description \\
\hline Position & ID & An object that the humanoid is on. \\
\hline PositionInRoad & {$[\mathrm{mm}]$} & $\begin{array}{l}\text { a length from the StartPoint of road when the } \\
\text { humanoid is on a road, otherwise it is zero }\end{array}$ \\
\hline HealthLevel & $\begin{array}{l}{[\text { health }} \\
\text { point }]\end{array}$ & $\begin{array}{l}\text { Health level of human. } \\
\text { The humanoid dies when this becomes zero }\end{array}$ \\
\hline DamagePoint & $\begin{array}{l}\text { [health } \\
\text { point }]\end{array}$ & $\begin{array}{l}\text { Health level dwindles by DamagePoint in } \\
\text { every cycle. DamagePoint becomes zero } \\
\text { immediately after the humanoid arrives at a } \\
\text { refuge }\end{array}$ \\
\hline
\end{tabular}

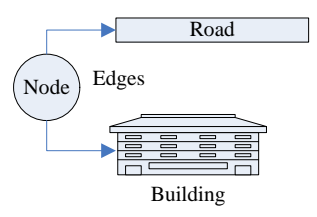

Figure 4. Node object

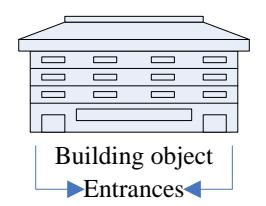

Figure 6. Building object

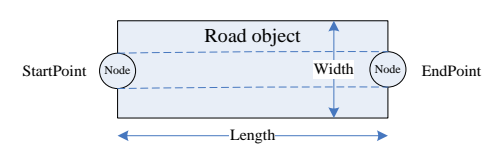

Figure 5. Road object

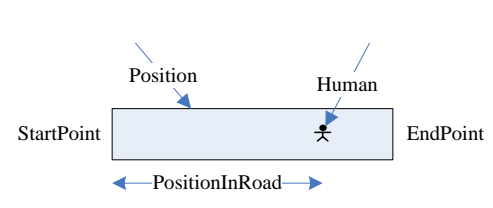

Figure 7. Human object
The topographical relations of objects are illustrated from Figure 4 to Figure 7 . The representative point is assigned to every object, and the distance between two objects is calculated from their representative points.

\section{Task Allocation Model}

The decision making of volunteers to help disabled persons can be treated as a task allocation problem [10-14]. The task allocation for rescue scenario is carried out by the central agents. The task of volunteers is to help disabled persons; this task has to be allocated as to which volunteers should help which disabled persons in order to maximize the number of survivals.

We utilize the combinatorial auction mechanism to solve this task allocation problem. At this model, the volunteers are the bidders; the disabled persons are the items; and the emergency center is the auctioneer. The distance and health level of disabled person are used as the cost for the bid. When the rescue process starts, emergency center creates a list of victims, sets the initial distance for victims, and broadcasts the information to all the volunteer agents. Only the volunteer agents whose distance to victims is less than the initial distance will help these victims. It means that each volunteer agent just help the victims within the initial distance instead of helping all the victims. The initial distance will help volunteers to reduce the number of task so that the decision making will be faster.

The aim of this task allocation model is to minimize the evacuation time. It is equivalent to minimize the total cost to accomplish all tasks. In this case, the cost is the sum of distance from volunteers to victims and the health level of victims. The optimization problem is formed as follows.

Given the set of $\mathrm{n}$ volunteers as bidders: $\mathrm{V}=\left\{\mathrm{v}_{1}, \mathrm{v}_{2}, \ldots, \mathrm{v}_{\mathrm{n}}\right\}$ and set of $\mathrm{m}$ disabled persons considered as $\mathrm{m}$ tasks: $\mathrm{D}=$ $\left\{\mathrm{d}_{1}, \mathrm{~d}_{2}, \ldots, \mathrm{d}_{\mathrm{m}}\right\}$. The distances from volunteers to disabled persons; distances among dsabled persons and health level of disabled persons are formulated as follow.

$\mathrm{M}\left[\mathrm{v}_{\mathrm{i}}, \mathrm{d}_{\mathrm{j}}\right]_{\mathrm{t}}=\left\{\mathrm{m}_{\mathrm{ij}} \mid \mathrm{m}_{\mathrm{ij}}\right.$ : distances from volunteer $\mathrm{v}_{\mathrm{i}}$ to disable person $\mathrm{d}_{\mathrm{j}}$ at time step $\left.\mathrm{t}\right\}$

$\mathrm{N}\left[\mathrm{d}_{\mathrm{i}}, \mathrm{d}_{\mathrm{j}}\right]=$

$\left\{n_{i j} \mid n_{i j}\right.$ : distances from disabled person $d_{i}$ to disabled person $\left.d_{j}\right\}$

$\mathrm{H}\left[\mathrm{d}_{\mathrm{i}}\right]_{\mathrm{t}}$

$=\left\{\mathrm{h}_{\mathrm{i}} \mid \mathrm{h}_{\mathrm{i}}\right.$ : health level of disabled person $\mathrm{d}_{\mathrm{i}}$ at time step $\mathrm{t} ; \mathrm{h}_{\mathrm{i}}$ $\in\{100,200,300,400,500\}\}$

Given the $\operatorname{Bid}_{v_{i}}\left(\left\{d_{j}, d_{q} \ldots d_{k}, d_{l}\right\}\right.$, cost $)$; With the cost $=\left(m_{i j}+\right.$ $\left.\mathrm{n}_{\mathrm{jq}}+\cdots+\mathrm{n}_{\mathrm{kl}}+\mathrm{h}_{\mathrm{j}}+\mathrm{h}_{\mathrm{q}}+\cdots+\mathrm{h}_{\mathrm{k}}+\mathrm{h}_{\mathrm{l}}\right)$

Let $I$ is a collection of subsets of $D$. Let $x_{j}=1$ if the $j^{\text {th }}$ set in I is a winning bid and $c_{j}$ is the cost of that bid. Also, let $a_{i j}=1$ if the $j^{\text {th }}$ set in I contains $i \in D$. The problem can then be stated as follows [15]:

$$
\begin{gathered}
\min \sum_{j \in I} c_{j} x_{j} \\
\text { With constraint } \sum_{j \in I} a_{i j} x_{j} \leq 1 \forall i \in D
\end{gathered}
$$


The constraint will make sure that each victim is helped by at most one volunteer.

To illustrate with an example of bid generation, let's assume that a volunteer A has information of 5 victims $\left(\mathrm{d}_{1}, \mathrm{~d}_{2}\right.$, $\mathrm{d}_{3}, \mathrm{~d}_{4}, \mathrm{~d}_{5}$ ). The initial distance is set to 200 meter. The volunteer estimates the distance from himself to each victims and select only victims who are not more than 200 meter from his location. Assume that, the victim $\mathrm{d}_{1}$ and victim $\mathrm{d}_{2}$ are selected to help with the cost is 180.1. The bid submitted to center agent is $\operatorname{Bid}_{\mathrm{A}}=\left(\left\{\mathrm{d}_{1}, \mathrm{~d}_{2}\right\}, 180.1\right)$.

This optimization problem can be solved by Heuristic Search method of Branch-on-items (Sandholm, 2002). This method is base on the question: "Which volunteer should this victim be assigned to?". The nodes of search tree are the bids. Each path in the search tree consists of a sequence of disjoint bids. At each node in the search tree, it expands the new node with the smallest index among the items that are still available, and do not include items that have already been used on the path. The solution is a path which has minimum cost in the search tree.

To illustrate with an example of a task allocation of volunteers to help disabled persons, let's assume that there are four volunteers and 3 disabled persons; The initial distance is set to 200 meter; At the time $\mathrm{t}^{\mathrm{th}}$ of simulation, distances from volunteers to disabled persons, the distance among disabled persons, and health level of disabled persons are assumed as follows.

$$
\begin{gathered}
\mathrm{M}\left[\mathrm{v}_{\mathrm{i}}, \mathrm{d}_{\mathrm{j}}\right]_{\mathrm{t}}=\left[\begin{array}{ccl}
280 & 260 & 50 \\
40 & 300 & 100 \\
250 & 100 & 150 \\
40 & 70 & 250
\end{array}\right] \\
\mathrm{N}\left[\mathrm{d}_{\mathrm{i}}, \mathrm{d}_{\mathrm{j}}\right]=\left[\begin{array}{ccl}
0 & 100 & 110 \\
100 & 0 & 70 \\
110 & 70 & 0
\end{array}\right] \quad \mathrm{H}\left[\mathrm{d}_{\mathrm{i}}\right]_{\mathrm{t}}=\{400,200,300\}
\end{gathered}
$$

For example, the volunteer $\mathrm{v}_{2}$ can make three bids for victim $\left\{\mathrm{d}_{1}\right\},\left\{\mathrm{d}_{3}\right\}$ and $\left\{\mathrm{d}_{1}, \mathrm{~d}_{3}\right\}$ based on initial distance. The cost for $\left\{d_{1}, d_{3}\right\}=m_{21}+n_{13}+h_{1}+h_{3}=40+110+400+$ $300=850$

Possible bids are listed as below.

$$
\begin{gathered}
\mathrm{B}_{\mathrm{v}_{1}}\left(\left\{\mathrm{~d}_{3}\right\}, 350\right) ; \mathrm{B}_{\mathrm{v}_{2}}\left(\left\{\mathrm{~d}_{1}\right\}, 440\right) ; \mathrm{B}_{\mathrm{v}_{2}}\left(\left\{\mathrm{~d}_{3}\right\}, 400\right) ; \mathrm{B}_{\mathrm{v}_{2}}\left(\left\{\mathrm{~d}_{1}, \mathrm{~d}_{3}\right\},\right. \\
850) ; \mathrm{B}_{\mathrm{v}_{3}}\left(\left\{\mathrm{~d}_{2}\right\}, 300\right) ; \mathrm{B}_{\mathrm{v}_{3}}\left(\left\{\mathrm{~d}_{3}\right\}, 450\right) ; \mathrm{B}_{\mathrm{v}_{4}}\left(\left\{\mathrm{~d}_{1}\right\}, 440\right) ; \\
\mathrm{B}_{\mathrm{v}_{4}}\left(\left\{\mathrm{~d}_{2}\right\}, 270\right) ; \mathrm{B}_{\mathrm{v}_{4}}\left(\left\{\mathrm{~d}_{1}, \mathrm{~d}_{2}\right\}, 740\right) ;
\end{gathered}
$$

\section{TASKS ALLOCATION AND COST}

\begin{tabular}{|l|l|l|l|}
\hline Bid & Volunteer & Disabled person & Cost \\
\hline $\mathrm{b}_{1}$ & $\mathrm{v}_{1}$ & $\left\{\mathrm{~d}_{3}\right\}$ & 350 \\
\hline $\mathrm{b}_{2}$ & $\mathrm{v}_{2}$ & $\left\{\mathrm{~d}_{1}\right\}$ & 440 \\
\hline $\mathrm{b}_{3}$ & $\mathrm{v}_{2}$ & $\left\{\mathrm{~d}_{3}\right\}$ & 400 \\
\hline $\mathrm{b}_{4}$ & $\mathrm{v}_{2}$ & $\left\{\mathrm{~d}_{1}, \mathrm{~d}_{3}\right\}$ & 850 \\
\hline $\mathrm{b}_{5}$ & $\mathrm{v}_{3}$ & $\left\{\mathrm{~d}_{2}\right\}$ & 300 \\
\hline $\mathrm{b}_{6}$ & $\mathrm{v}_{3}$ & $\left\{\mathrm{~d}_{3}\right\}$ & 450 \\
\hline $\mathrm{b}_{7}$ & $\mathrm{v}_{4}$ & $\left\{\mathrm{~d}_{1}\right\}$ & 440 \\
\hline $\mathrm{b}_{8}$ & $\mathrm{v}_{4}$ & $\left\{\mathrm{~d}_{2}\right\}$ & 270 \\
\hline $\mathrm{b}_{9}$ & $\mathrm{v}_{4}$ & $\left\{\mathrm{~d}_{1}, \mathrm{~d}_{2}\right\}$ & 740 \\
\hline
\end{tabular}

The bid $b_{2}$ and $b_{7}$ have the same task $\left\{d_{1}\right\} ; b_{5}$ and $b_{8}$ have the same task $\left\{d_{2}\right\} ; b_{1}, b_{3}$ and $b_{6}$ have the same task $\left\{d_{3}\right\}$. The more expensive bids will be removed.

\begin{tabular}{|l|l|l|l|}
\hline Bid & Volunteer & Disabled person & Cost \\
\hline $\mathrm{b}_{1}$ & $\mathrm{v}_{1}$ & $\left\{\mathrm{~d}_{3}\right\}$ & 350 \\
\hline $\mathrm{b}_{2}$ & $\mathrm{v}_{2}$ & $\left\{\mathrm{~d}_{1}, \mathrm{~d}_{3}\right\}$ & 850 \\
\hline $\mathrm{b}_{3}$ & $\mathrm{v}_{4}$ & $\left\{\mathrm{~d}_{1}\right\}$ & 440 \\
\hline $\mathrm{b}_{4}$ & $\mathrm{v}_{4}$ & $\left\{\mathrm{~d}_{2}\right\}$ & 270 \\
\hline $\mathrm{b}_{5}$ & $\mathrm{v}_{4}$ & $\left\{\mathrm{~d}_{1}, \mathrm{~d}_{2}\right\}$ & 740 \\
\hline
\end{tabular}

Then, the search tree is formed as below.

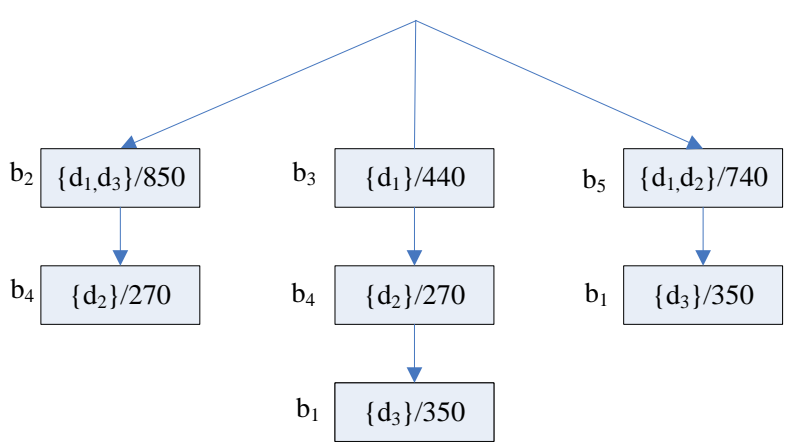

Figure 8. Branch on Items based Search tree

The winner path is $b_{3}, b_{4} b_{1}$, which has the most minimum cost of 1060. The task allocation solution: volunteer $\mathrm{v}_{4}$ will help disabled persons $\mathrm{d}_{1}$ and $\mathrm{d}_{2}$; volunteer $\mathrm{v}_{1}$ will help disabled persons $\mathrm{d}_{3}$.

\section{EXPERIMENTAL RESULTS}

In this section, we present experimental studies on different scenarios. The goal is to examine the proposed method of task allocation model for selecting disabled people to rescue. The evacuation time is evaluated from the time at which the first volunteer start moving until the time at which all alive victims arrive at the shelters. The simulation model is tested using the RoboCup platform with Morimoto Traffic Simulator[17].

\section{A. Experimental Settings}

We consider the number of volunteers, number of disabled persons, and traffic density as parameters to examine the correlation between these parameters with rescue time.

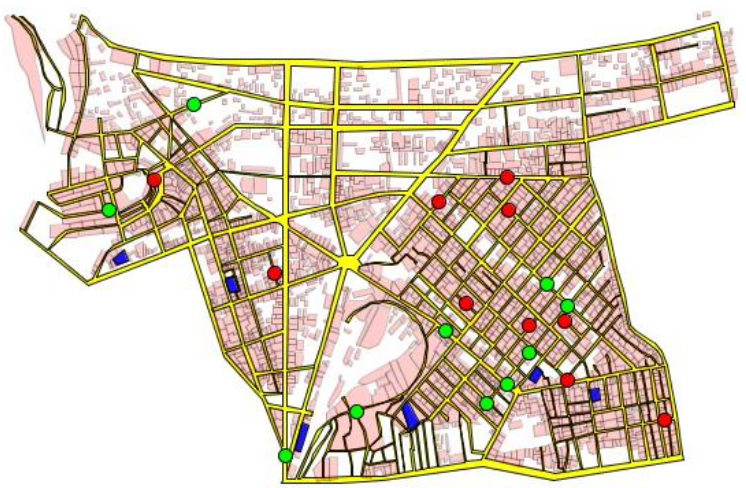

Figure 9. Sample GIS Map 
The sample GIS map consists of 5 layers: road, building, volunteer, disabled person and shelter. The red points and green points indicate the locations of disabled persons and locations of volunteers respectively. These locations are generated randomly along the roads. Blue buildings are shelters. The initial health level of disabled persons are generated randomly between 100 to 500. Every time step of simulation, these health levels decrease by 0.5 . If the health level is equal to zero, the corresponding agent is considered as dead. The movements of volunteer agents are controlled by Morimoto Traffic Simulator.

\section{B. Experimental results}

With a fixed number of disabled persons and the number of volunteers increase, the correlation between number of volunteers and rescue time is shown as below.

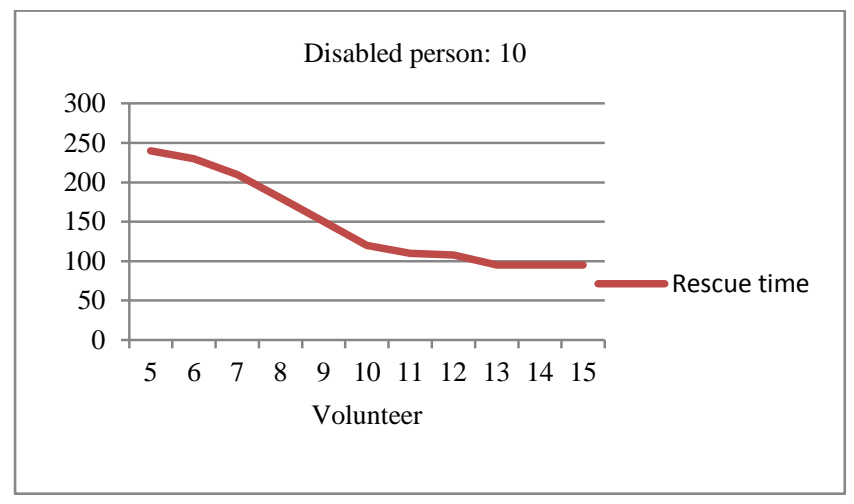

Figure 10. Correlation between Number of Volunteers and Rescue Time

With a fixed number of volunteers and the number of disabled persons increase, the correlation between number of disabled persons and rescue time is shown as below.

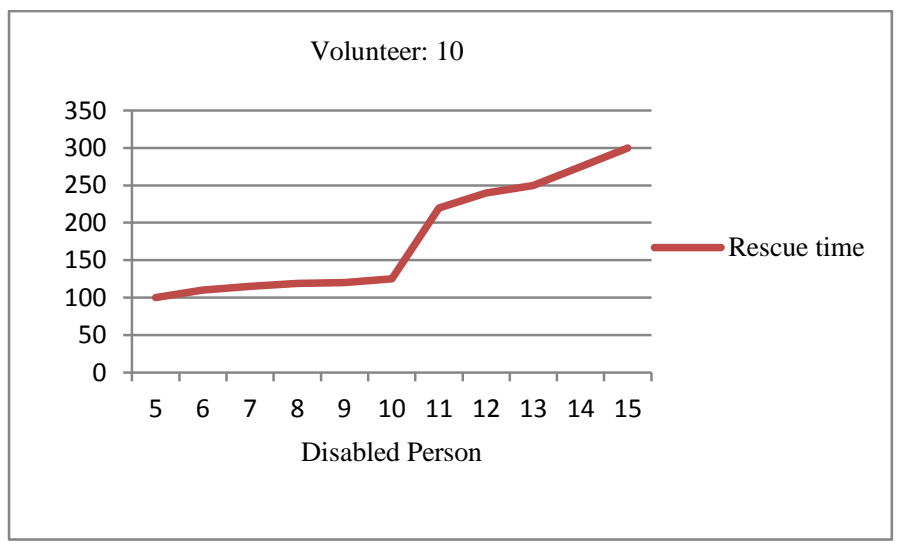

Figure 11. Correlation between Number of Disabled Persons and Rescue Time

The number of volunteers and the number of disabled persons are fixed, whereas the number of vehicle increases. We test with the total length of road of 500 meters. The increasing number of vehicles will make traffic density higher. The correlation between number of vehicle and rescue time is shown as below.
Volunteer: $10 \quad$ Disabled person: 10

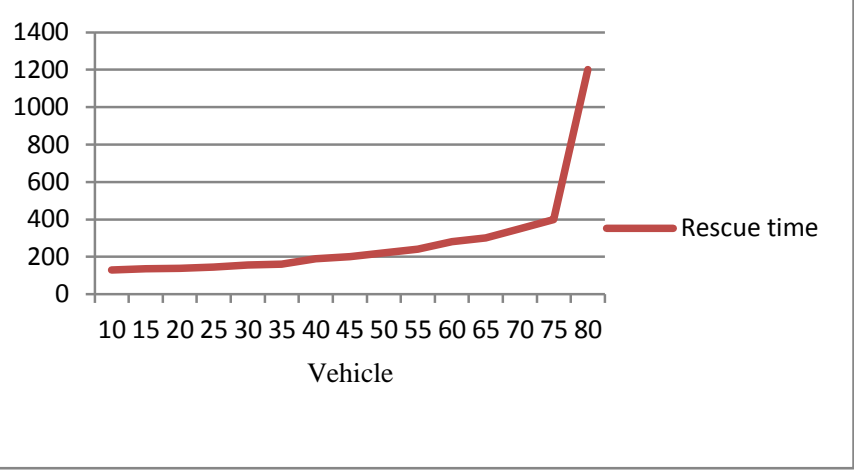

Figure 12. Correlation between Number of Vehicles and Rescue Time

\section{CONCLUSION}

In this paper, the decision making of volunteers to help persons with disability is presented as task allocation problem. The disabled persons are considering as the tasks, and these tasks are allocated to volunteers by utilizing combinatorial auctions mechanism. At each time step of simulation, the task allocation problem is solved in order to assign appropriate tasks to volunteers. Although there are some previous works [13, 14] on applying combinatorial auctions to task allocation, our method has some differences in forming and solving problem; the volunteers only bid on disabled persons located within a certain distance and the health condition of disabled persons and the distance from volunteers to disabled persons are used as the cost of bids. The simple example of task allocation problem is presented to clarify the procedures of our method. The RoboCup rescue simulation platform is used to simulate the rescue process. The correlations between rescue time and other parameters such as number of volunteers, number of disabled persons and number of vehicles are also presented.

In future work, we are thinking of comparing the multicriteria decision making method with task allocation method in case of solving the decision making problem of volunteers to help disabled persons.

\section{REFERENCES}

[1] C. Ren, C. Yang, and S. Jin, "Agent-Based Modeling and Simulation on emergency", Complex 2009, Part II, LNICST 5, 1451 - 1461, 2009.

[2] M. H. Zaharia , F. Leon, C. Pal, and G. Pagu, "Agent-Based Simulation of Crowd Evacuation Behavior", International Conference on Automatic Control, Modeling and Simulation, 529-533, 2011.

[3] C. T. Quang, and A. Drogoul, "Agent-based simulation: definition, applications and perspectives", Invited Talk for the biannual Conference of the Faculty of Computer Science, Mathematics and Mechanics, 2008.

[4] Z. Bo, and V. Satish, "Agent-based modeling for household level hurricane evacuation", Winter Simulation Conference, 2009.

[5] J. W. Cole, C. E. Sabel, E. Blumenthal,K. Finnis, A. Dantas,S. Barnard, and D. M. Johnston, "GIS-based emergency and evacuation planning for volcanic hazards in New Zealand", Bulletin of the New Zealand society for earthquake engineering, vol. 38, no. 3, 2005.

[6] M. Batty, "Agent-Based Technologies and GIS: simulating crowding, panic, and disaster management", Frontiers of geographic information technology, chapter 4, 81-101, 2005 
[7] T. Patrick, and A. Drogoul, "From GIS Data to GIS Agents Modeling with the GAMA simulation platform", TF SIM 2010.

[8] C. T. Quang, A. Drogoul, and A. Boucher, "Interactive Learning of Independent Experts' Criteria for Rescue Simulations", Journal of Universal Computer Science, Vol. 15, No. 13, 2701-2725, 2009.

[9] S. Silvia, C. John, and L. Beatriz, "Improving Rescue Operation in Disasters. Approaches about Task Allocation and Re-scheduling", In Proceedings of PLANSIG 2005, London UK, 2005.

[10] R. Nair, T. Ito, M. Tambe, and S.Marsella, "Task allocation in the rescue simulation domain: A short note", Volume 2377 of Lecture Notes in Computer Science. Springer, Berlin 751-754, 2002.

[11] F. Boffo, P. R. Ferreira, and A. L. Bazzan, "A comparison of algorithms for task allocation in robocup rescue", Proceedings of the 5th European workshop on multiagent systems, 537-548, 2007.

[12] L. Hunsberger, B. Grosz, "A combinatorial auction for collaborative planning", Proceedings of the fourth international conference on multiagent systems, 2000.

[13] L. Beatriz, S. Silvia, and L. Josep, "Allocation in rescue operations using combinatorial auctions", Artificial Intelligence Research and Development, Vol. 100, 233-243, 2003.

[14] C. K. Chan, and H. F. Leung, "Multi-auction approach for solving task allocation problem", Lecture Notes in Computer Science, Vol 4078, 240-254, 2005.

[15] T. Sandholm, "Algorithm for optimal winner determination in combinatorial auctions", Artificial Intelligence, Vol 135, 1-54, 2002.

[16] K. Arai \& T. X. Sang, "Multi Agent-based Rescue Simulation for Disable Persons with the Help from Volunteers in Emergency Situations", International Journal of Research and Reviews in Computer Science (IJRRCS) Vol. 3, No. 2, April 2012.
[17] Morimoto, "Traffic Simulator for RoboCupRescue Prototype Simulation System", Available at: http://www.robocuprescue.org/docs/traffic.txt

\section{AUTHORS PROFILE}

Kohei Arai, He received his BS, MS and PhD degrees in 1972, 1974 and 1982, respectively. He was with The Institute for Industrial Science and Technology of the University of Tokyo from April 1974 to December 1978 and also was with National Space Development Agency of Japan from January, 1979 to March, 1990. From 1985 to 1987, he was with Canada Centre for Remote Sensing as a Post-Doctoral Fellow of National Science and Engineering Research Council of Canada. He moved to Saga University as a Professor in the Department of Information Science on April 1990. He was a counselor for the Aeronautics and Space related to the Technology Committee of the Ministry of Science and Technology during from 1998 to 2000. He was a councilor of Saga University for 2002 and 2003. He also was an executive councilor for the Remote Sensing Society of Japan for 2003 to 2005. He is an Adjunct Professor of University of Arizona, USA since 1998. He also is Vice Chairman of the Commission A of ICSU/COSPAR since 2008. He wrote 29 books and published 262 journal papers.

Tran Xuan Sang, He received his Bachelor degree in Computer Science from Vinh University, Vietnam, 2003 and a Master degree in Information Technology for Natural Resources Management from Bogor Agricultural University, Indonesia, 2006. From April, 2010 to present, he is a doctoral student at the Department of Information Science, Faculty of Science and Engineering, Saga University, Japan. His research interests include expert system, intelligent computing, GIS modeling and simulation.

Nguyen Thi Uyen, She received her Bachelor degree in Computer Science from Vinh University, Vietnam, 2009. From September, 2009 to present, she is a lecturer at Faculty of Information and Technology, Vinh University, Vietnam. Her research interests include expert system and intelligent computing. 